\title{
Electrochemistry
}

\section{CHARACTERIZATION OF A NOVEL DIOXOMOLYBDENUM COMPLEX BY CYCLIC VOLTAMMETRY}

\author{
Esther Theresa Knittl, ${ }^{1}$ D. A. Rusakov, ${ }^{2} \odot$ E. I. Korotkova, ${ }^{2}$ \\ E. V. Dorozhko, ${ }^{2}$ O. A. Voronova, ${ }^{2}$ E. V. Plotnikov, \\ Isil Topaloglu-Sozuer, ${ }^{3}$ and Wolfgang Linert ${ }^{1}$ \\ ${ }^{1}$ Institute of Applied Synthetic Chemistry, Vienna University of Technology, \\ Vienna, Austria \\ ${ }^{2}$ National Research Tomsk Polytechnic University, Tomsk, Russia \\ ${ }^{3}$ Chemistry Department, Izmir Institute of Technology, Urla, \\ Gulbahce, Turkey
}

Metalloenzymes that carry a pterin-based molybdenum cofactor in their center catalyze numerous reactions in the human body and play a crucial role in its metabolism. Specifically, these enzymes promote redox reactions and oxygen transport in the body. Their absence may cause many problems leading to disability or even death in early childhood. Therefore, model compounds need to be synthesized and analyzed to investigate the reactivity, redox potential, and geometry of these cofactors. This study focused on electrode processes and determined the redox potentials of the new bis-(4-mercapto-5(p-tolyl)-3H-1,2-dithiole-3-thione)-dioxomolybdenum complex by cyclic voltammetry. The 4-mercapto-5-(p-tolyl)-3H-1,2-dithiole-3-thione ligand underwent irreversible oxidation and reduction at thiol and thione functional groups. The new dioxomolybdenum complex showed a quasi-reversible two-stage electrode process.

Keywords: Cyclic voltammetry; Dioxomolybdenum complex; Glassy carbon electrode; Redox properties

\section{INTRODUCTION}

Molybdenum is an abundant microelement present in specific organic and inorganic compounds. Organic molybdenum compounds exist in living species, such as bacteria, animals, and humans. The physiological significance of molybdenum in animals and humans was first demonstrated in 1953 upon the discovery of its effect on xanthine oxidase activity (Holm, Kennepohl, and Solomon 1996; Enemark et al. 2004). In addition to promoting the activity of antioxidants, such as vitamin C, molybdenum plays a key role in cellular respiration systems and enhances amino acid synthesis and nitrogen accumulation (Holm 1990; Enemark and Young 1993).

Received 18 January 2015; accepted 31 March 2015.

Address correspondence to Elena Dorozhko, National Research Tomsk Polytechnic University, Tomsk, Russia. E-mail: elena-dorozhko@yandex.ru 
Oxomolybdenum complexes have proven important in practical applications (Sellmann et al. 1995; Schwarz, Mendel, and Ribbe 2009). In particular, oxomolybdenum (VI) complexes play a central role in industrial and biochemical catalysis (Jorgensen 1989; Rao, Munshi, and Rao 2000). They catalyze olefin epoxidation and hydroxylation (Brito et al. 2004), alcohol oxidation (Lorber, Smidt, and Osborn 2000), and biochemical reactions involving oxygen atom transfer (Holm 1990).

Molybdenum only exhibits biological activity in its enzymatic oxomolybdenum complex, in which it catalyzes biochemical reactions and plays a crucial role in human metabolism (Dinda et al. 2002). It is present as a molybdenum cofactor (Rajagopalan and Johnson 1992; Kisker, Schindelin, and Rees 1997; Hille 2002; Sigel and Sigel 2002) in sulfite oxidase, which participates in the metabolism of sulfur-containing amino acids; xanthine oxidase, which promotes purine and pyrimidine oxidation as well as uric acid production; and aldehyde oxidase. In addition to one molybdenum atom, the molybdenum cofactor comprises one or two oxo ligands with sulfur ligands and/or an amino acid residue (such as serine or cysteine) (Hille 1996). Molybdenum cofactor deficiency may lead to the development of numerous diseases and even cause death in infants (Schwarz 2005), highlighting the high relevance of synthetic cofactors. Existing studies on these model compounds have addressed reactivity, spatial structure, and redox potential determination. Redox potential data are expected to predict electron transfer properties in various biochemical reactions (Lenaz and Milazzo 1997; Bard, Stratmann, and Wilson 2002).

In this study, bis-(4-mercapto-5-(p-tolyl)-3H-1, 2-dithiole-3-thione)-dioxomolybdenum was synthesized and evaluated for the first time. The electrode processes and redox potentials of this new dioxomolybdenum complex bearing sulfur-containing ligands were investigated by cyclic voltammetry, which is considered as the most reliable and sensitive method to characterize reactions on the electrode surface.

The diversity of molybdenum valence forms depends on the presence of stable molybdenum compounds in different oxidation states and chemical activity, making the choice of an appropriate working electrode material as the key task. Platinum and glassy carbons are typically used as working electrode materials. A platinum metal working electrode may yield erroneous results because molybdenum and platinum produce numerous intermetallic compounds that may subsequently affect electrode processes (Scholtz 2006). Therefore, a glassy carbon electrode (GCE), which has proven suitable in studies on electrode processes in aprotic solvents at potentials below -1.0 volt with respect to the chlorine electrode, was employed as the working electrode in this study.

\section{MATERIALS AND METHODS}

\section{Equipment}

The electrochemical properties of the 4-mercapto-5-(p-tolyl)-3H-1, 2-dithiole3 -thione bidentate sulfur donor ligand and the dioxomolybdenum complex were determined using a VoltaLab 40 system (Radiometer analytical). A thermostated three-electrode cell (Radiometer Analytical) equipped with a capillary to bubble nitrogen gas through solutions served as the electrochemical cell. While a glassy carbon electrode acted as the working electrode, a pseudo-electrode consisting of a 
silver wire submerged in ferrocene solution was used as the reference electrode. Ferrocene was added to the cell at the end of the measurement series, and the potential of its redox couple reverse peak was assumed to be the control point on the electrode potential scale $\left(E_{1 / 2}=0.0\right.$ volt). A plate-shaped platinum electrode was used as an auxiliary electrode. Prior to the analytical procedure, impurities were mechanically removed from the working electrode by sequential surface polishing using alumina powder and a soft cloth before drying under nitrogen. All experiments were conducted at $(23 \pm 0.2)$ degree Celsius.

\section{Preparation of Background Solutions}

Experiments were conducted under strict anaerobic conditions for chemical systems requiring an oxygen-free atmosphere in organic solvents such as tetrahydrofuran. Anhydrous tetrahydrofuran was purified using the PureSolv system (Innovative Technology Systems, Inc.).

The electrochemical cell was dried under vacuum using a hot air flow. The electrolyte $\mathrm{N}\left(\mathrm{C}_{4} \mathrm{H}_{9}\right)_{4} \mathrm{PF}_{4}$ was then placed in the cell under argon atmosphere and dried under vacuum until it melted. Because of its hygroscopic nature, the electrolyte was purified by dissolution in dichloromethane, recrystallized at 0 degree Celsius, dried at 100 degree Celsius for approximately twenty hours, and stored in a glove box under an inert atmosphere. The background solution was prepared under an inert atmosphere.

A solution of 0.1 mole per liter $\mathrm{N}\left(\mathrm{C}_{4} \mathrm{H}_{9}\right)_{4} \mathrm{PF}_{4}$ in an aprotic solvent was selected as an optimal conducting background solution to investigate the electrochemical properties of the bidentate sulfur donor ligand and the dioxomolybdenum complex.

\section{Preparation of Analyte Solutions}

The analyte $(0.010 \pm 0.005$ gram $)$ was dissolved in the background solution (6 milliliters). Background and solutions of interest were analyzed for potentials ranging from -2.0 to 1.0 volts at scan rates of $50,100,150,200$, and 250 millivolts per second. Each cycle was repeated three times. After the measurements, ferrocene was added to the solutions as an internal standard.

\section{RESULTS AND DISCUSSION}

\section{Electrochemical Properties of the Ligand}

The electrochemical properties of the 4-mercapto-5-(p-tolyl)-3H-1,2-dithiole-3thione ligand were initially investigated by cyclic voltammetry at potentials from +1.0 to -2.0 volts using a glassy carbon electrode in tetrahydrofuran. The sulfurcontaining ligand was synthesized according to a known procedure (Adams et al. 2004). For a simpler and more convenient representation of the possible electrode processes occurring on a glassy carbon electrode, the ligand was shown to include thiol $(\mathrm{R}-\mathrm{SH})$ and thione $\left(\mathrm{R}^{\prime} \mathrm{C}=\mathrm{S}\right)$ moieties. The cyclic voltammogram of the ligand in tetrahydrofuran is shown in Figure 1. 


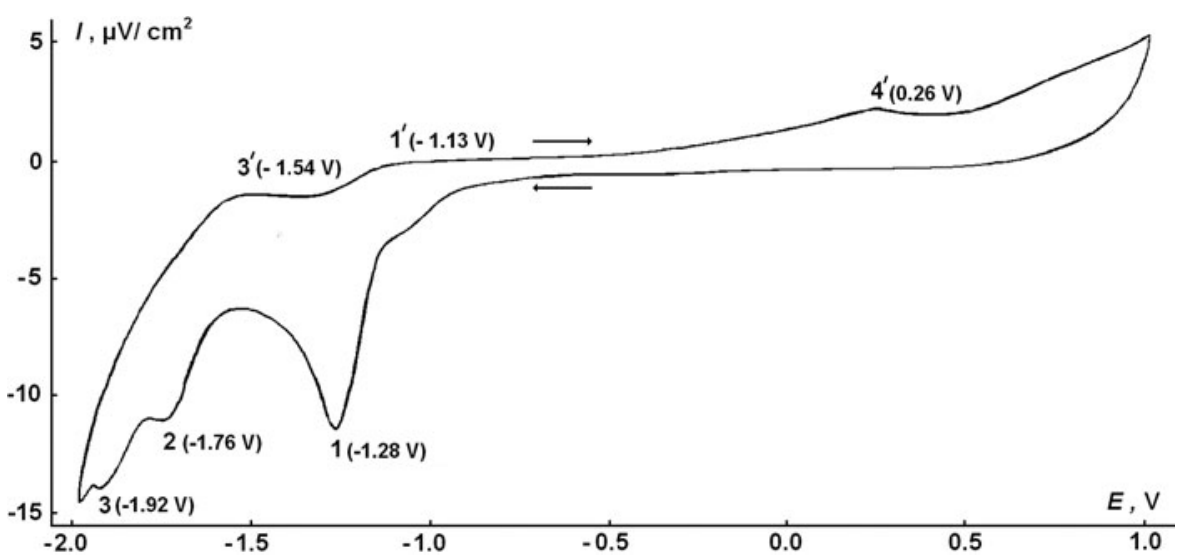

Figure 1. Cyclic voltammogram of $1 \times 10^{-3}$ moles per liter 4-mercapto-5-(p-tolyl)-3H-1, 2-dithiole-3thione in 0.1 molar $\mathrm{N}\left(\mathrm{C}_{4} \mathrm{H}_{9}\right)_{4} \mathrm{PF}_{4}$ in tetrahydrofuran on a glassy carbon electrode at a scan rate of 50 millivolts per second referenced against the ferrocene redox couple ( 0 volt here).

The cyclic voltammogram showed several peaks corresponding to ligand reduction and oxidation, indicating that the ligand exhibits a complex electrochemical behavior because of the presence of electrochemically active thiol and thione groups, consistent with previous reports (Bradbury et al. 1981; McNaughton et al. 2000; Borsari, Cannio, and Gavioli 2003; Fotouhi et al. 2003; Schulzke 2005). The cyclic voltammogram (Figure 1) consisted of three cathodic and anodic peaks, which clearly represented different electrode processes. The peak corresponding to ligand reduction (1) at a potential of -1.28 volts exhibited the highest intensity. The anodic peak current $1^{\prime}\left(\mathrm{Ipa}_{1}\right)$ was detected at a potential of -1.13 volts Electrode process $1 / 1^{\prime}$ in aprotic solvents, which is attributed to the oxidation/reduction of sulfohydride groups (Bradbury et al. 1981), is defined as follows:

$$
\mathrm{R}-\mathrm{SH}+\bar{e} \underset{1^{\prime}(-1.13 \mathrm{~V})}{\stackrel{1(-1.28 \mathrm{~V})}{\leftrightarrows}} \mathrm{R}-\mathrm{S}^{-}+\frac{1}{2} \mathrm{H}_{2}
$$

The effect of the scan rate on the ligand cathodic $\left(I \mathrm{pc}_{1}\right)$ and anodic peak current $\left(I \mathrm{pa}_{1}\right)$ as well as their corresponding potentials $\left(E \mathrm{pc}_{1}, E \mathrm{pa}_{1}\right)$ was studied to define electrode process $1 / 1^{\prime}$. Cyclic voltammetry data for electrode process $1 / 1^{\prime}$ are listed in Table 1.

Table 1. Cyclic voltammetry of 4-mercapto-5-(p-tolyl)-3H-1, 2-dithiole-3-thione for electrode process $1 / 1^{\prime}$ at various scan rates

\begin{tabular}{lcccccc}
\hline Scan rate, \\
$\begin{array}{l}\text { millivolts } \\
\text { per second }\end{array}$ & $\begin{array}{c}\text { Anodic peak } \\
\text { potential, } \\
\text { millivolts }\end{array}$ & $\begin{array}{c}\text { Cathodic } \\
\text { peak } \\
\text { potential, } \\
\text { millivolts }\end{array}$ & $\begin{array}{c}\text { Anodic and } \\
\text { cathodic peak } \\
\text { potential difference, } \\
\text { millivolts }\end{array}$ & $\begin{array}{c}\text { Anodic peak } \\
\text { current, } \\
\text { millivolts }\end{array}$ & $\begin{array}{c}\text { Cathodic } \\
\text { peak } \\
\text { current, } \\
\text { microampere }\end{array}$ & $\begin{array}{c}\text { Anodic } \\
\text { and cathodic } \\
\text { peak current } \\
\text { ratio }\end{array}$ \\
\hline 50 & -1146 & -1270 & 124 & 1.20 & 6.50 & 0.18 \\
100 & -1142 & -1274 & 132 & 1.40 & 7.00 & 0.20 \\
150 & -1129 & -1279 & 150 & 1.50 & 7.42 & 0.20 \\
200 & -1134 & -1286 & 152 & 1.40 & 8.05 & 0.17 \\
250 & -1130 & -1288 & 158 & 2.00 & 10.83 & 0.18 \\
\hline
\end{tabular}




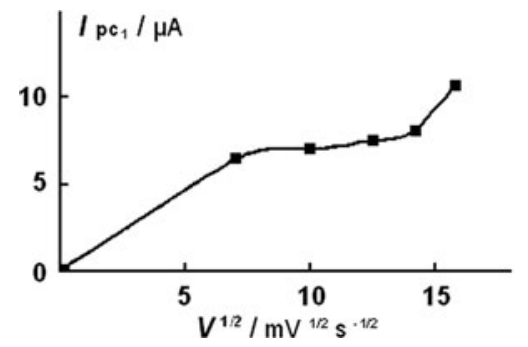

Figure 2. The dependence of cathodic wave current $\left(I_{\mathrm{pc} 1}\right)$ on potential scan rates $\left(V^{1 / 2}\right)$ for $1 \times 10^{-3}$ moles per liter 4-mercapto-5-(p-tolyl)-3H-1, 2-dithiole-3-thione in 0.1 molar $\mathrm{N}\left(\mathrm{C}_{4} \mathrm{H}_{9}\right)_{4} \mathrm{PF}_{4}$ in tetrahydrofuran on a glassy carbon electrode for electrode process $1 / 1^{\prime}$.

For electrode process $1 / 1^{\prime}, I \mathrm{pc}_{1}$ and $I \mathrm{pa}_{1}$ increased when the scan rate increased from 50 to 250 millivolts per second. Cathodic potentials shifted toward negative values, whereas their anodic counterparts shifted toward positive values. The ratio between anodic and cathodic peak currents $I \mathrm{pa}_{1} / \mathrm{Ipc}_{1}$ was below one and remained approximately constant within the entire scan rate range. Furthermore, the dependence of $I \mathrm{pc}_{1}$ and $I \mathrm{pa}_{1}$ on the scan rate raised to the power of $1 / 2\left(V^{1 / 2}\right)$ was nonlinear (Figures 2 and 3 ). These findings indicate that electrode process $1 / 1^{\prime}$ on a glassy carbon electrode was electrochemically irreversible (Nicholson and Shain 1964; Laviron 1980).

A previous study on the electrochemical behavior of sulfur-containing compounds (Moiroux, Deycard, and Fleury 1983; Nomura 2011) showed that the R'C=S group produces a radical when reduced at more negative potentials ranging from -1.5 to -2.0 volts. This radical is unstable and rapidly dimerizes into a disulfide, which yields an anion upon reduction. Similar electrochemical behavior was observed for the thione moiety of 4-mercapto-5-(p-tolyl)-3H-1,2-dithiole-3-thione.

According to cyclic voltammetry (Figure 1), electrode processes 2 and $3 / 3^{\prime}$ involving the thione moiety of 4-mercapto-5-(p-tolyl)-3H-1,2-dithiole-3-thione were also irreversible. These electrode processes are described as follows:

$$
\mathrm{R}^{\prime} \mathrm{C}=\mathrm{S}+\bar{e}+\mathrm{H}^{+} \stackrel{2(-1.76 \mathrm{~V})}{\rightleftarrows} \mathrm{R}^{\prime} \mathrm{CHS}^{\bullet}
$$

$$
2 \mathrm{R}^{\prime} \mathrm{CHS}^{\bullet} \rightarrow \mathrm{R}^{\prime} \mathrm{CHSSCHR}^{\prime}
$$

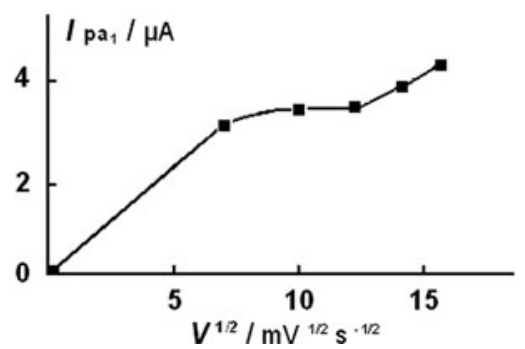

Figure 3. The dependence of anodic wave current $\left(I_{\mathrm{pa} 1}\right)$ on potential scan rates $\left(V^{1 / 2}\right)$ for $1 \times 10^{-3}$ moles per liter 4-mercapto-5-(p-tolyl)-3H-1, 2-dithiole-3-thione in 0.1 molar $\mathrm{N}\left(\mathrm{C}_{4} \mathrm{H}_{9}\right)_{4} \mathrm{PF}_{4}$ in tetrahydrofuran on a glassy carbon electrode for electrode process $1 / 1^{\prime}$. 


$$
\mathrm{R}^{\prime} \mathrm{CHSSCHR}+2 \bar{e} \underset{3^{\prime}(-1.54 \mathrm{~V})}{\stackrel{3(-1.92 \mathrm{~V})}{\leftrightarrows}} 2 \mathrm{R}^{\prime} \mathrm{CHS}^{-}
$$

The cyclic voltammogram displayed a signal corresponding to ligand oxidation $\left(4^{\prime}\right)$ in the anodic region at a potential of +0.26 volt (Figure 1$)$. In this potential range, the thiol anion ( $\mathrm{R}-\mathrm{S}^{-}$) was presumably oxidized into a radical (Bradbury et al. 1981; Borsari, Cannio, and Gavioli 2003), and subsequent dimerization of the unstable thiol radicals produces a disulfide, as shown in Equations (5) and (6):

$$
\begin{gathered}
\mathrm{R}-\mathrm{S}^{-} \stackrel{4^{\prime}(+0.26 \mathrm{~V})}{\longrightarrow} \mathrm{R}-\mathrm{S}^{\bullet}+\bar{e} \\
2 \mathrm{R}-\mathrm{S}^{\bullet} \rightarrow \mathrm{R}-\mathrm{S}-\mathrm{S}-\mathrm{R}
\end{gathered}
$$

Therefore, 4-mercapto-5-(p-tolyl)-3H-1, 2-dithiole-3-thione undergoes oxidation and reduction at thiol and thione moieties. Electrode process $1 / 1^{\prime}$ corresponds to the irreversible oxidation-reduction of the thiol group, while electrode processes 2 and $3 / 3^{\prime}$ represent the irreversible oxidation-reduction of the thione moiety. Electrode process $4^{\prime}$ corresponds to the irreversible oxidation of the thiol anion into disulfide.

\section{Electrochemical Properties of the Dioxomolybdenum Complex}

The electrochemical properties of bis-(4-mercapto-5-(p-tolyl)-3H-1,2-dithiole3-thione)-dioxomolybdenum were also studied by cyclic voltammetry on a glassy carbon electrode. The dioxomolybdenum complex was synthesized according to a published procedure (Adams et al. 2004).

All measurements were conducted in anhydrous tetrahydrofuran because of the extremely low solubility of the dioxomolybdenum complex. The measurements were conducted at scan rates ranging from +1.0 to -2.0 volt at a complex concentration

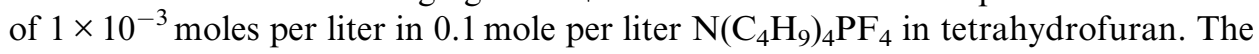

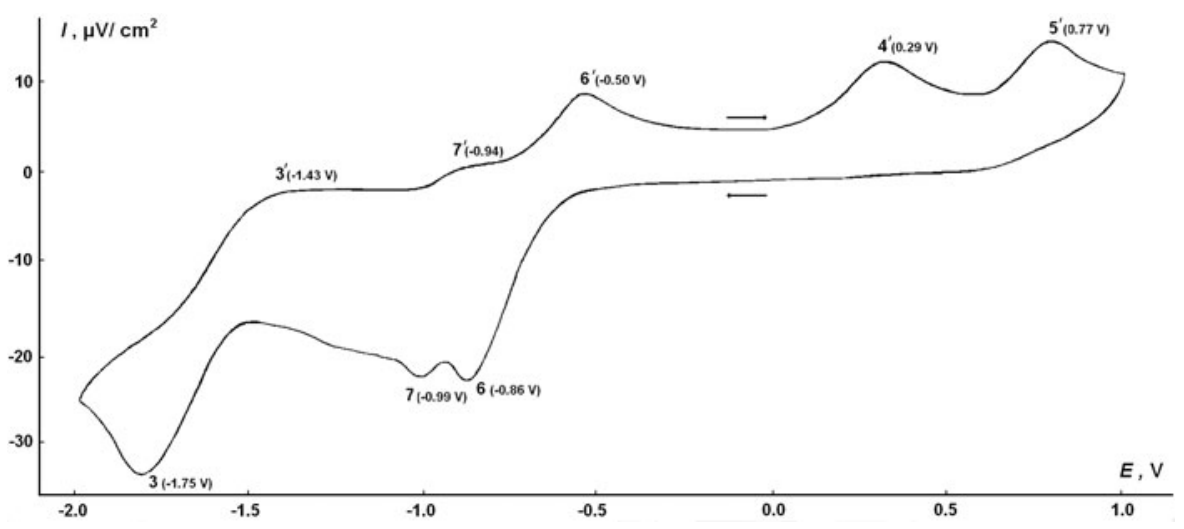

Figure 4. Cyclic voltammogram of $1 \times 10^{-3}$ moles per liter bis-(4-mercapto-5-(p-tolyl)-3H-1,2-dithiole-3thione) dioxomolybdenum in 0.1 molar $\mathrm{N}\left(\mathrm{C}_{4} \mathrm{H}_{9}\right)_{4} \mathrm{PF}_{4}$ in tetrahydrofuran on a glassy carbon electrode at a scan rate of 50 millivolts per seconds referenced against the ferrocene redox couple ( 0 volt here). 
cyclic voltammogram of the dioxomolybdenum complex displayed several reduction and oxidation peaks corresponding to different electrode processes (Figure 4).

In addition to typical peaks attributable to the reduction and oxidation of sulfur-containing ligand functional groups, the cyclic voltammogram (Figure 4) presented new peaks for the oxidation-reduction of molybdenum in the complex. Furthermore, its shape was independent of the scan rate direction during the polarization of the glassy carbon electrode. Therefore, the number and positions of the peaks remain unchanged.

Electrode processes $6 / 6^{\prime}$ and $7 / 7^{\prime}$ [Equations (7) and (8)] may correspond to the stepwise reduction and oxidation of the dioxomolybdenum complex:

$$
\begin{gathered}
{\left[\mathrm{Mo}^{\mathrm{VI}} \mathrm{O}_{2}(\text { ligand })_{2}\right]+\bar{e} \underset{6^{\prime}(-0.50 \mathrm{~V})}{\stackrel{6(-0.86 \mathrm{~V})}{\rightleftarrows}}\left[\mathrm{Mo}^{\mathrm{V}} \mathrm{O}_{2}(\text { ligand })_{2}\right]^{-}} \\
{\left[\mathrm{Mo}^{\mathrm{V}} \mathrm{O}_{2}(\text { ligand })_{2}\right]^{-}+\bar{e} \underset{7^{\prime}(-0.94 \mathrm{~V})}{\stackrel{7(-0.99 \mathrm{~V})}{\rightleftarrows}}\left[\mathrm{Mo}^{\mathrm{IV}} \mathrm{O}_{2}(\text { ligand })_{2}\right]^{2-}}
\end{gathered}
$$

Recharge potentials for $\mathrm{Mo}^{\mathrm{VI}} \leftrightarrows \mathrm{Mo}^{\mathrm{VI}}$ in dioxomolybdenum complexes usually range from -0.4 to -1.0 volt depending on the conducting environment (Bradbury et al. 1981). Therefore, electrode processes $6 / 6^{\prime}$ and $7 / 7^{\prime}$ (Figure 4) may be assigned to the two-stage oxidation-reduction $\left.\left[\mathrm{Mo}^{\mathrm{VI}} \mathrm{O}_{2} \text { (ligand) }\right)_{2}\right] \leftrightarrows\left[\mathrm{Mo}^{\mathrm{IV}} \mathrm{O}_{2}(\text { ligand })_{2}\right]^{2-}$ [Equations (7) and (8)].

The oxomolybdenum complex $\left[\mathrm{Mo}^{\mathrm{VI}} \mathrm{O}_{2}(\text { ligand })_{2}\right]$ may give the radical $\left(\mathrm{S}^{\circ} \mathrm{R}^{\prime}\right)$ through several chemical reactions. This radical subsequently may undergo dimerization via the ligand thione moiety:

$$
\begin{gathered}
{\left[\mathrm{Mo}^{\mathrm{VI}} \mathrm{O}_{2}(\text { ligand })_{2}\right] \rightarrow\left[\mathrm{Mo}^{\mathrm{V}} \mathrm{O}_{2}(\text { ligand })\right]+\mathrm{S}^{\bullet} \mathrm{R}^{\prime}} \\
2 \mathrm{~S}^{\bullet} \mathrm{R}^{\prime} \rightarrow \mathrm{R}^{\prime} \mathrm{SSR}^{\prime}
\end{gathered}
$$

Therefore, electrode process $3 / 3^{\prime}$ (Figure 4 ) at -0.8 and -1.5 volts may correspond to the oxidation-reduction of the thione group into disulfide as follows:

$$
\mathrm{R}^{\prime} \mathrm{SSR}^{\prime}+2 \bar{e} \underset{3^{\prime}(-1.43 \mathrm{~V})}{\stackrel{3(-1.75 \mathrm{~V})}{\rightleftarrows}} 2 \mathrm{R}^{\prime} \mathrm{S}^{-}
$$

Reduction and oxidation potentials were nearly identical in the cyclic voltammograms (Figures 1 and 4) for the $3 / 3^{\prime}$ peaks, confirming that the disulfide form of the ligand participates in electrode process $3 / 3^{\prime}$.

Furthermore, dioxomolybdenum complexes may be involved in anion formation by the ligand:

$$
\left[\mathrm{Mo}^{\mathrm{V}} \mathrm{O}_{2}(\text { ligand })\right]+\left[\mathrm{Mo}^{\mathrm{V}} \mathrm{O}_{2}(\text { ligand })_{2}\right]^{-} \rightarrow\left[\mathrm{Mo}_{2}{ }_{2} \mathrm{O}_{4}(\text { ligand })_{2}\right]+\mathrm{R}^{\prime} \mathrm{S}^{-}
$$

The resulting anion $\mathrm{R}^{\prime} \mathrm{S}^{-}$may undergo two-stage oxidation [Equations (13)-(15)], giving rise to irreversible signals $4^{\prime}$ and $5^{\prime}$ in the cyclic voltammogram (Figure 4).

$$
\mathrm{R}^{\prime} \mathrm{S}^{-} \stackrel{4^{\prime}(+0.29 \mathrm{~V})}{\longrightarrow} \mathrm{R}^{\prime} \mathrm{S}^{\bullet}
$$


Table 2. Cyclic voltammetry of the dioxomolybdenum complex for electrode process $6 / 6^{\prime}$ at various scan rates

\begin{tabular}{lcccccc}
\hline $\begin{array}{l}\text { Scan rate, } \\
\text { millivolts } \\
\text { per second }\end{array}$ & $\begin{array}{c}\text { Anodic peak } \\
\text { potential, } \\
\text { millivolts }\end{array}$ & $\begin{array}{c}\text { Cathodic } \\
\text { peak } \\
\text { potential, } \\
\text { millivolts }\end{array}$ & $\begin{array}{c}\text { Anodic and cathodic } \\
\text { peak potential } \\
\text { difference, millivolts }\end{array}$ & $\begin{array}{c}\text { Anodic } \\
\text { peak } \\
\text { current, } \\
\text { millivolts }\end{array}$ & $\begin{array}{c}\text { Cathodic } \\
\text { peak current, cathodic peak } \\
\text { millivolts } \\
\text { current ratio }\end{array}$ & $\begin{array}{c}\text { Anodic and } \\
\text { mo }\end{array}$ \\
\hline 50 & -649 & -876 & 227 & 5.5260 & 6.315 & 0.875 \\
100 & -625 & -850 & 225 & 5.8820 & 5.588 & 1.052 \\
200 & -608 & -887 & 279 & 6.4280 & 6.428 & 1.000 \\
250 & -572 & -875 & 303 & 6.8180 & 6.363 & 1.070 \\
\hline
\end{tabular}

$$
\begin{gathered}
2 \mathrm{R}^{\prime} \mathrm{S}^{\bullet} \rightarrow \mathrm{R}^{\prime} \mathrm{SSR}^{\prime} \\
\mathrm{R}^{\prime} \mathrm{SSR}^{\prime} \stackrel{5^{\prime}(+0.77 \mathrm{~V})}{\longrightarrow}\left[\mathrm{R}^{\prime} \mathrm{SSR}^{\prime}\right]^{+}
\end{gathered}
$$

The effect of scan rate variations between 50 and 250 millivolts per second on voltammetric signals $6 / 6^{\prime}$ and $7 / 7^{\prime}$ was studied to identify electrode processes $6 / 6^{\prime}$ and $7 / 7^{\prime}$ corresponding to the stepwise oxidation-reduction of molybdenum in the complex. Cyclic voltammetry results of electrode processes $6 / 6^{\prime}$ and $7 / 7^{\prime}$ are listed in Tables 2 and 3, respectively.

Cathodic $\left(I \mathrm{pc}_{6}\right)$ and anodic peak $\left(\mathrm{Ipa}_{6}\right)$ currents increased with scan rate for electrode process $6 / 6^{\prime}$. Cathodic potentials shifted toward negative values, while their anodic counterparts shifted toward positive values. Furthermore, the ratio between anodic and cathodic peak currents $I \mathrm{pa}_{6} / \mathrm{Ipc}_{6}$ was approximately one and remained virtually unchanged over the entire scan rate range. These findings demonstrate that process $6 / 6^{\prime}$ on a glassy carbon electrode is diffusion-controlled and electrochemically reversible (Nicholson and Shain 1964; Laviron 1980). On the other hand, the $\Delta E \mathrm{p}$ value increased from 7 to 108 millivolts with increasing scan rate (Table 2). The dependence of $I \mathrm{pc}_{6}$ and $I \mathrm{pa}_{6}$ on $V^{1 / 2}$ exhibited a nonlinear trend. As a result, electrode process $6 / 6^{\prime}$ is quasi-reversible instead of reversible.

Conventional criteria used to define an electrode process and the data in Table 3 suggested similar conclusions about the electrochemical quasi-reversibility of the electrode process $7 / 7^{\prime}$. In addition to the nonlinear dependence of $\mathrm{Ipc}_{7}$ and $I \mathrm{pa}$ on $V^{1 / 2}$, the $I \mathrm{pa}_{7} / \mathrm{Ipc}_{7}$ ratio remained quasi-constant around one over the entire scan

Table 3. Cyclic voltammetry of the dioxomolybdenum complex for electrode process $7 / 7^{\prime}$ at various scan rates

\begin{tabular}{lcccccc}
\hline $\begin{array}{l}\text { Scan rate, } \\
\text { millivolts } \\
\text { per second }\end{array}$ & $\begin{array}{c}\text { Anodic peak } \\
\text { potential, } \\
\text { millivolts }\end{array}$ & $\begin{array}{c}\text { Cathodic } \\
\text { peak } \\
\text { potential, } \\
\text { millivolts }\end{array}$ & $\begin{array}{c}\text { Anodic and cathodic } \\
\text { peak potential } \\
\text { difference, millivolts }\end{array}$ & $\begin{array}{c}\text { Anodic } \\
\text { peak } \\
\text { current, } \\
\text { millivolts }\end{array}$ & $\begin{array}{c}\text { Cathodic } \\
\text { peak current, cathodic peak } \\
\text { millivolts }\end{array}$ & $\begin{array}{c}\text { Anodic and } \\
\text { current ratio }\end{array}$ \\
\hline 50 & -938 & -996 & 51 & 1.315 & 1.526 & 0.86 \\
100 & -918 & -969 & 58 & 0.888 & 0.888 & 1.00 \\
150 & -930 & -999 & 69 & 1.071 & 1.071 & 1.00 \\
200 & -916 & -1007 & 91 & 1.363 & 1.363 & 1.00 \\
250 & -902 & -1021 & 119 & 1.000 & 1.000 & 1.00 \\
\hline
\end{tabular}


rate range, and $I \mathrm{pc}_{7}$ and $I \mathrm{pa}_{7}$ values increased when cathodic potentials shifted toward negative values and their anodic counterparts shifted toward positive values, confirming this quasi-reversibility.

\section{CONCLUSIONS}

The electrochemical properties of the dioxomolybdenum complex and its sulfur-containing ligand were studied by cyclic voltammetry. The ligand was oxidized and reduced at thiol and thione functional groups through irreversible electrode processes. A two-stage electrode process $\left[\mathrm{Mo}^{\mathrm{VI}} \mathrm{O}_{2}(\text { ligand })_{2}\right]^{0} \leftrightarrows\left[\mathrm{Mo}^{\mathrm{IV}} \mathrm{O}_{2}(\text { ligand })_{2}\right]^{2-}$ was observed from the redox properties of the dioxomolybdenum complex. Conventional criteria used to identify electrode processes revealed that electrode processes were quasi-reversible.

\section{ORCID}

Dmitriy Rusakov @ http://orcid.org/0000-0002-2929-1409

\section{REFERENCES}

Adams, H., L.-M. Chung, M. J. Morris, and P. J. Wright. 2004. A convenient route to 4-mercapto-1,2-dithiole-3-thiones from terminal alkynes. Tetrahedron Letters 45(41): 7671-74. doi:10.1016/j.tetlet.2004.08.091

Bard, A. J., M. Stratmann, and G. S. Wilson. 2002. Encyclopedia of Electrochemistry, Bioelectrochemistry, Vol. 9. Wiley VCH.

Borsari, M., M. Cannio, and G. Gavioli. 2003. Electrochemical behavior of diphenyl disulfide and thiopenol on glassy carbon and gold electrodes in aprotic media. Electroanalysis 15(14): 1192-97. doi:10.1002/elan.200390146

Bradbury, J. R., A. F. Masters, A. C. McDonell, A. A. Brunette, A. M. Bond, and A. C. Wedd. 1981. Redox properties of thiolate compounds of oxomolybdenum (V) and their tungsten and selenium analogs. Journal of the American Chemical Society 103(8): 1959-64. doi:10.1021/ja00398a014

Brito, J. A., M. Gomez, G. Muller, H. Teruel, J.-C. Clinet, E. Dunach, and M. A. Maestro. 2004. Structural studies of mono- and dimetallic MoVI complexes? A new mechanistic contribution in catalytic olefin epoxidation provided by oxazoline ligands. European Journal of Inorganic Chemistry 21: 4278-85. doi:10.1002/ejic.200400331

Dinda, R., P. Sengupta, H. Mayer-Figge, and W. S. Sheldrick. 2002. A family of mononuclear molybdenum-(VI), and -(IV) oxo complexes with a tridentate (ONO) ligand. Journal of the Chemical Society, Dalton Transactions 23: 4434-39. doi:10.1039/b207129k

Enemark, J. H., J. J. A. Cooney, J.-J. Wang, and R. H. Holm. 2004. Synthetic analogues and reaction systems relevant to the molybdenum and tungsten oxotransferases. Chemical Reviews 104(2): 1175-200. doi:10.1021/cr020609d

Enemark, J. H., and C. G. Young. 1993. Bioinorganic chemistry of pterin-containing molybdenum and tungsten enzymes. Advances in Inorganic Chemistry 40: 1-88. doi:10.1016/ s0898-8838(08)60181-6

Fotouhi, L., N. Farzinnegad, M. M. Heravi, and Sh. Khaleghi. 2003. Study the electrochemical reduction of some triazines in N,N-dimethylformamide at glassy carbon electrode. Bulletin of the Korean Chemical Society 24(12): 1751-56. 
Hille, R. 1996. The mononuclear molybdenum enzymes. Chemical Reviews 96(7): 2757-816. doi:10.1002/chin.199710272

Hille, R. 2002. Molybdenum and tungsten in biology. Trends in Biochemical Sciences 27(7): 360-67. doi:10.1016/s0968-0004(02)02107-2

Holm, R. H. 1990. The biologically relevant oxygen atom transfer chemistry of molybdenum: From synthetic analogue systems to enzyme. Coordination Chemistry Reviews 100: 183-221. doi:10.1016/0010-8545(90)85010-p

Holm, R. H., P. Kennepohl, and E. I. Solomon. 1996. Structural and functional aspects of metal sites in biology. Chemical Reviews 96(7): 2239-14. doi:10.1021/cr9500390

Jorgensen, K. A. 1989. Transition-metal-catalyzed epoxidations. Chemical Reviews 89(3): 431-58. doi:10.1021/cr00093a001

Kisker, C., H. Schindelin, and D. C. Rees. 1997. Molybdenum-cofactor-containing enzymes: Structure and mechanism. Annual Review of Biochemistry 66: 233-67.

Laviron, E. 1980. A multilayer model for the study of space distributed redox modified electrodes: Part I. Description and discussion of the model. Journal of Electroanalytical Chemistry and Interfacial Electrochemistry 112(1): 1-9. doi:10.1016/s0022-0728(80) 80002-7

Lenaz, G., and G. Milazzo. 1997. Bioelectrochemistry of Biomacromolecules (Bioelectrochemistry - Principles and Practice), Vol. 5. Basel, Switzerland: Birkhauser.

Lorber, C. Y., S. P. Smidt, and J. A. Osborn. 2000. Selective and environmentally benign aerobic catalytic oxidation of alcohols by a molybdenum-copper system. European Journal of Inorganic Chemistry 4: 655-58.

McNaughton, R. L., A. A. Tipton, N. D. Rubie, R. R. Conry, and M. L. Kirk. 2000. Electronic structure studies of oxomolybdenum tetrathiolate complexes: Origin of reduction potential differences and relationship to cysteine-molybdenum bonding in sulfite oxidase. Inorganic Chemistry 39(25): 5697-706. doi:10.1021/ic0003729

Moiroux, J., S. Deycard, and M. B. Fleury. 1983. Electrochemical behavior of 1,2-dithiole-3thiones. Journal of Electroanalytical Chemistry and Interfacial Electrochemistry 146(2): 313-31. doi:10.1016/s0022-0728(83)80592-0

Nicholson, R. S., and I. Shain. 1964. Theory of stationary electrode polarography. Single scan and cyclic methods applied to reversible, irreversible, and kinetic systems. Analytical Chemistry 36(4): 706-23. doi:10.1021/ac60210a007

Nomura, M. 2011. Organometallic dithiolene complexes of the group 8-10 metals: Reactivities, structures and electrochemical behavior. Dalton Transactions 40(10): 2112-40. doi:10.1039/ c0dt01025a

Rajagopalan, K. V., and J. L. Johnson. 1992. The pterin molybdenum cofactors. Journal of Biological Chemistry 267: 10199-202.

Rao, S. N., K. N. Munshi, and N. N. Rao. 2000. Catalytic oxidation of styrene using cis$\mathrm{MoO}_{2}(\mathrm{~L})($ solv) $[\mathrm{L}=$ salicylidene salicyloyl hydrazine) and its zeolite composite as catalysts in the presence of molecular oxygen. Journal of Molecular Catalysis A: Chemical 156(1-2): 205-11. doi:10.1016/s1381-1169(99)00413-6

Scholtz, F. 2006. Electroanalytical Methods. Moscow, Russia: Binom. Laboratoriya Znanii (In Russian).

Schulzke, C. 2005. Temperature dependent electrochemical investigations of molybdenum and tungsten oxobisdithiolene complexes. Dalton Transactions 4: 713-20. doi:10.1039/ b414853c

Schwarz, G. 2005. Molybdenum cofactor biosynthesis and deficiency. Cellular and Molecular Life Sciences 62(23): 2792-10. doi:10.1007/s00018-005-5269-y

Schwarz, G., R. R. Mendel, and M. W. Ribbe. 2009. Molybdenum cofactors, enzymes and pathways. Nature 460: 839-47. doi:10.1038/nature08302 
Sellmann, D., B. Hadawi, F. Knoch, and M. Mool. 1995. Transition-metal complexes with sulfur ligands. Syntheses, X-ray crystal structures, and reactivity of molybdenum(II) complexes with thioetherthiolate ligands having XS4 donor atom sets $(\mathrm{X}=\mathrm{S}, \mathrm{O}, \mathrm{NH})$. Inorganic Chemistry 34(24): 5963-72. doi:10.1021/ic00128a006

Sigel, A., and H. Sigel. 2002. Molybdenum and Tungsten - Their Roles in Biological Processes. New York, NY: Marcell Decker. 